\title{
Incidence of depression, anxiety and stress following traumatic injury: a longitudinal study
}

Taneal A Wiseman ${ }^{1,2^{*}}$, Kate Curtis ${ }^{1,2}$, Mary Lam ${ }^{1}$ and Kim Foster ${ }^{1,3}$

\begin{abstract}
Background: Traumatic injury and mental health disorders are co-associated. Early identification of depression, anxiety and stress following injury, and subsequent preventive intervention, may reduce the long-term symptoms and negative impacts associated with depression and anxiety. The purpose of the study was to determine the incidence, severity and predictors of depression, anxiety and stress in injured patients in the acute phase of care, and at six months following injury, as well as the effectiveness of an in-hospital screening tool.

Methods: This descriptive longitudinal study of trauma patients was conducted at a Level 1 Metropolitan Trauma Centre in Australia over 14 months. Participants were interviewed using the Depression Anxiety Stress Scale short-form version (DASS-21) during hospital admission then at 3 and 6 months after injury. Descriptive statistics were performed to evaluate participant characteristics and incidence of depression, anxiety and stress. Correlations and logistic regression were conducted to investigate the ability of the DASS-21 to predict symptoms of depression, anxiety and stress and to investigate factors associated with depression, anxiety and stress 6 months after injury.

Results: 201 participants ranging in age (18-94 years) and injury severity participated in the baseline interview and 109 completed all 3 interviews over 6 months. Over half (54\%) reported above normal scores for depression, anxiety and/or stress in at least one of the 3 time points. Intensive care unit admission and high levels of depression, anxiety and stress at 3 months post injury were predictors for high levels of depression, anxiety and stress at 6 months. Low scores for depression, anxiety and stress during admission were correlated with low scores for depression, anxiety and stress at 3 and 6 months.
\end{abstract}

Conclusion: Depression, anxiety and stress in patients hospitalised following injury is common and should be anticipated in patients who have had an intensive care admission. Screening at 3 months following injury identifies patients at risk of long-term symptoms of depression, anxiety and stress.

Keywords: Depression, Anxiety, Stress, Injury, Mental health, Patient outcome, Screening

\section{Introduction}

Traumatic injury is responsible for $11 \%$ of global mortality and contributes to a significant amount of physical and psychological morbidity for all age groups [1]. Patients with traumatic injury report a substantial reduction in health-related quality of life compared to other patients, including long-term psychological and physical disability [2]. The psychological impact of injury includes the development of acute and long-term mental health

\footnotetext{
* Correspondence: taneal.wiseman@sesiahs.health.nsw.gov.au

'Sydney Nursing School, University of Sydney, Camperdown 2050, NSW, Australia

${ }^{2}$ Trauma Service, St George Hospital, Kogarah 2217, NSW, Australia

Full list of author information is available at the end of the article
}

problems such as post-traumatic stress, depression and anxiety.

Posttraumatic stress disorder (PTSD) is the most frequently researched mental health problem following injury. Acute stress disorder (ASD) [3] can progress to PTSD if symptoms persist after one month with approximately $50 \%$ of those with PTSD initially presenting with ASD [4]. Acute stress disorder occurs in up to $45 \%$ of injury survivors [5], and involves an anxiety response that includes re-experience of the traumatic event, intrusive memories, dreams, and strong emotional distress on exposure to triggering events [4].

Anxiety has also been found to occur in injury survivors $[1,6]$, with anxiety identified in up to $40 \%$ of injury

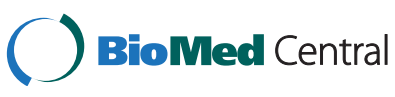

(c) 2015 Wiseman et al.; licensee BioMed Central. This is an Open Access article distributed under the terms of the Creative Commons Attribution License (http://creativecommons.org/licenses/by/4.0), which permits unrestricted use, distribution, and reproduction in any medium, provided the original work is properly credited. The Creative Commons Public Domain Dedication waiver (http://creativecommons.org/publicdomain/zero/1.0/) applies to the data made available in this article unless otherwise stated. 
survivors [7-9]. Some characteristic symptoms of anxiety include; hyper arousal and physical symptoms such as increased respirations and dry mouth. Depression has been identified in up to $42 \%$ of injury survivors, from as early as 6 weeks to as long as 20 years post injury $[8,9]$. Characteristic symptoms of depression include feelings of prolonged unhappiness, lethargy and a general lack of interest in the environment and self [3,6].

Despite the known associations between injury, depression, anxiety, ASD and PTSD, there is limited knowledge on the combined presence and extent of depression, anxiety and stress symptoms in injured patients over time [7]. Further, there is little evidence on effective early screening tools, and the implementation of screening tools, for these problems in the injured population [7-10]. The purpose of the study was to determine the incidence, severity and predictors of depression, anxiety and stress in injured patients in the six months following injury and use the findings to inform strategy for effective psychosocial follow-up care of injured patients.

\section{Aims of the study}

The aims of the study were to:

- Determine the incidence and severity of Depression, Anxiety and Stress post injury, during hospital admission and at 3 and 6 months following admission.

- Identify factors associated with higher levels of depression, anxiety and stress in patients post injury.

\section{Patients and methods}

\section{Design and setting}

This was a descriptive longitudinal quantitative study. Following ethics approval (HREC/10/SGH/198), data were collected over 14-months from May 2011 to August 2012 at a Level 1 Trauma Centre in Australia. Depression, anxiety, and stress levels were determined during a structured interview at 3 time points; during hospital admission, 3 months, and 6 months post injury.

\section{Sample size}

Calculations for the primary analyses were based on a repeated measures analysis of variance exploring change over time between the three injury severity groups on DASS-21 subscales (main and interaction effects). With 3 time periods, a medium effect size $\mathrm{f}$ of 0.25 , alpha of 0.01 (to account for multiple testing) and $80 \%$ power, a total sample size of 150 was required. Additional participants were recruited $(n=201)$ to account for the loss to follow-up associated with longitudinal research.

\section{Participants}

All patients aged 18 years and over admitted to the study site meeting trauma admission criteria were screened for inclusion irrespective of injury mechanism, severity of injury or background. Trauma admission criteria are based on mechanism of injury, physiologic and injury criteria. For example, motor vehicle collision (MVC) greater than $55 \mathrm{kph}$, assault, or fall from height $>3$ metres. Patients were excluded if they had a pre-existing cognitive impairment such as dementia or traumatic brain injury resulting in existing cognitive impairment. All patients included in the study provided written consent prior to the collection of any data.

\section{Tools}

The study site trauma registry was used to obtain demographic, injury and outcome data. Participant levels of depression, anxiety and stress were assessed using the short form version of the Depression Anxiety and Stress Scale (DASS-21) [11].

The DASS 21 is a validated self-report tool consisting of three 7-item subscales, assessing the related negative emotion states of depression, anxiety and stress, using a fourpoint Likert scale ranging from 0-3 (Never, Sometimes, Often and Almost Always) to indicate the frequency with which the particular emotion had been felt over the past week [11]. For example, 'I found it difficult to work up the initiative to do things' and 'I felt that I was using a lot of nervous energy'. The scores are tallied according to the respective sub-scales (Depression, Anxiety or Stress). As the DASS -21 is a short form version of the DASS -42 , the subscale scores were doubled per the DASS -21 manual prior to categorisation and analysis. Symptom severity ratings for each sub-scale were assigned, ranging from normal to extremely severe, indicating the severity of symptoms [11] (Table 1). The DASS- 21 has a number of strengths and was chosen because it is validated for in and out of hospital use and has been proven to be a reliable screening tool for symptoms of depression, anxiety and stress, a feature unique to the DASS -21 and DASS -42 $[11,12]$. Further, it does not require specialist training to administer $[11,12]$. The DASS- 21 has been widely used in both clinical and non-clinical samples including the injured population [11-13]. The DASS -21 does not give as full detail about precise symptoms as the DASS -42 but has equal factor structure [10].

Table 1 Depression anxiety stress scale scores and clinical severity ratings

\begin{tabular}{llll}
\hline Ratings & Depression & Anxiety & Stress \\
\hline Normal & $0-9$ & $0-7$ & $0-14$ \\
Mild & $10-13$ & $8-9$ & $15-18$ \\
Moderate & $14-20$ & $10-14$ & $19-25$ \\
Severe & $21-27$ & $15-19$ & $26-33$ \\
Extremely Severe & $28+$ & $20+$ & $34+$ \\
\hline
\end{tabular}




\section{Data collection}

Participants were approached within fourteen days of their admission or extubation. An interpreter was used to approach non-English speaking patients $(\mathrm{n}=24)$. Following written consent the baseline DASS-21 was administered face to face by a researcher trained in structured interview technique and in managing potential participant distress. This interview was conducted at the patients' bedside while they were admitted to hospital [14]. Although the DASS-21 tool does not require specialist training for clinicians, in the context of the research training was deemed important to maintain consistency of administration and for supporting participant wellbeing. The 3 and 6 month interviews were conducted via telephone following a structured telephone interview guide [14]. All participants were given contact details for follow up emotional support services.

\section{Data management}

For data analysis a number of clinical categories were created. Polytrauma was defined as the patient having more than two injuries. This definition has been used widely in trauma research and is associated with subsequent long-term recovery [15] and higher treatment costs. Patients were grouped according to injury severity scores (ISS) of less than 9 (minor), 9-12 (moderate) and greater than 12 (major) [15]. For descriptive analyses, Depression, Anxiety and Stress scores were grouped in 3 categories: normal, mild/moderate, and severe/extremely severe as the aim of this research was to determine the incidence and severity of these reported symptoms. Hence, for analysis of predictors of depression, anxiety and stress, if a participant had a moderate, severe or extremely severe score in any of the depression, anxiety and stress subscales, they were allocated to a moderate and above group. An additional categorical variable was created using classification information for the moderate and above groups at baseline and at 3 months to capture the extent in which depression, anxiety and stress was experienced post injury. The categories were: Normal (did not experience moderate and above levels of depression, anxiety and stress scores in any of the 3 sub-scales at baseline and at 3 months); Baseline only (experienced moderate and above level of depression, anxiety and stress scores in any of the 3 sub-scales at baseline but not at 3 months); Persistent (experienced moderate and above level of depression, anxiety and stress score in any of the 3 sub-scales at baseline and at 3 months); Late onset (did not experience moderate and above level of depression, anxiety and stress score in any of the 3 sub-scales at baseline but experienced moderate and above level of depression, anxiety and stress score in any of the 3 sub-scales at 3 months).
Dummy variables were subsequently created for these categories for the logistic regression with "normal" as the reference group.

\section{Data analysis}

Data were analysed using SPSS 20 [16]. Descriptive statistics were conducted to determine sample representativeness in variables such as Mechanism of Injury, age and Injury Severity of the study participants and the eligible population over the 14-month data collection period. Descriptive statistics were also conducted to determine the incidence of depression, anxiety and stress at each time period. Pairwise comparisons were made between the two DASS-21 rating groups (moderate, severe or extremely severe versus normal and mild) to identify if any injury or demographic characteristic was associated with the levels of depression, anxiety and stress at each time point. Depending on the nature of the variable, the following statistical tests were used: T-test was used for the numeric age variable; MannWhitney test was used for ISS; $\chi^{2}$ test was used for categorical variables Polytrauma, Intensive Care Unit (ICU) Admission, and Injury mechanism.

Logistic regression was conducted to investigate factors that were associated with participants still experiencing a moderate or above level of depression, anxiety and stress 6 months after injury adjusting for other variables in the model with the intention of identifying significant predictors of the outcome (DASS) at 6 months post injury. These factors included whether participants sustained polytrauma as part of the injury, if they were admitted to ICU during their hospitalization for their injury, and whether they reported symptoms of depression, anxiety and stress post injury at either baseline or 3 months after injury (i.e. normal, baseline only, persistent, late onset). These variables were chosen to be included in the logistic regression based on their significant bivariate association with the reported levels on depression, anxiety and stress at 6 months at a significance of $\mathrm{p}<0.05$ level.

\section{Results}

During the study period, 1335 patients were screened and 1024 met study criteria. Of these, 823 declined to participate. Participants who volunteered reasons for declining included not wanting to be involved in a longitudinal study or that they did not feel comfortable providing contact details for follow up. The demographic and injury characteristics of the study sample were representative of the general trauma population at the study site during the recruitment period in respect to age and injury severity. The majority of the sample population were male (74.6\%) compared with $67.4 \%$ in the admitted trauma patient population which is expected 
and representative of the wider Australian major trauma population [17]. There were two main areas where there were differences in the study sample and the non -recruited admitted trauma patient population. Fewer patients in the sample group (10.4\%) had an intensive care unit (ICU) admission compared to the non-recruited trauma patient population $(17.5 \%)(\mathrm{p}=0.02)$, which is expected given the exclusion criteria. There was also a difference in the proportions of injury mechanism between the two groups, however all mechanisms were represented and this is not considered clinically significant (Table 2).

Of the study participants, one participant required a language translator. The mean age of participants was 49 years. The majority of the participants were male (74.6\%) and the median ISS was 9 (IQR 5-14). The injury mechanism most represented was fall greater than 1 metre (27.9\%), followed by motor vehicle collision
(MVC) driver (21.9\%) and motorbike collision (MBC) (15.9\%). More than two thirds (71.1\%) suffered polytrauma and $10.4 \%$ had an ICU admission. Of the 201 participants who completed the baseline interview, $122(60.7 \%)$ completed the 3-month interview and 109 (54.2\%) completed the 6 month interview.

\section{Incidence and severity of depression, anxiety and stress}

The mean scores of reported depression, anxiety and stress reduced over time (Table 3). At baseline, 74 (36.8\%) participants reported symptoms of depression above the normal range, 118 (58.7\%) had symptoms of anxiety above the normal range and similarly, 89 (54.3\%) had symptoms of stress above the normal range. Of these, $32(15.9 \%)$ reported extremely severe scores in the depression subscale, 45 (22.4\%) in anxiety, and 36 (17.9\%) in stress.

Table 2 Sample representativeness of the study population

\begin{tabular}{|c|c|c|c|c|}
\hline Characteristics & Total & Participants & Non-participants & Stat \\
\hline \multicolumn{5}{|l|}{ Patient demographics } \\
\hline Total number of patients (n) & 1335 & $201(15.1 \%)$ & 1134 (84.9\%) & \\
\hline \multicolumn{5}{|l|}{ Age (years) } \\
\hline Mean (SD) [Range] & 49 (23) [1-96] & 49 (18) [18-94] & 49 (24) [1-96] & $\mathrm{T}=0.09, \mathrm{df}=345.7, \mathrm{p}=0.929$ \\
\hline Gender (\%) & & & & $x^{2}=4.16, d f=1, p=0.041$ \\
\hline Female & $421(31.5 \%)$ & $51(25.4 \%)$ & $370(32.6 \%)$ & \\
\hline Male & $914(68.5 \%)$ & $150(74.6 \%)$ & $764(67.4 \%)$ & \\
\hline \multicolumn{5}{|l|}{ Clinical characteristics } \\
\hline \multicolumn{5}{|l|}{ ISS } \\
\hline Median (IQR) & $8(4-16)$ & $9(5-14)$ & $8(4-16)$ & $M W=108948.0, p=0.318$ \\
\hline Poly trauma (\%) & & & & $x^{2}=3.04, d f=1, p=0.081$ \\
\hline Yes & $878(65.8 \%)$ & $143(71.1 \%)$ & $735(64.8 \%)$ & \\
\hline No & $457(34.2 \%)$ & $58(28.9 \%)$ & $399(35.2 \%)$ & \\
\hline ICU admission (\%) & & & & $x^{2}=5.42, d f=1, p=0.020$ \\
\hline Yes & $181(16.4 \%)$ & $18(10.4 \%)$ & $163(17.5 \%)$ & \\
\hline No & $921(83.6 \%)$ & $155(89.6 \%)$ & $766(82.5 \%)$ & \\
\hline Mechanism of injury & & & & $x^{2}=50.70, d f=10, p<0.001$ \\
\hline Fall greater than 1 Meter & $464(35.1 \%)$ & $56(27.9 \%)$ & $408(36.4 \%)$ & \\
\hline MVC driver & $262(19.8 \%)$ & $44(21.9 \%)$ & $218(19.4 \%)$ & \\
\hline $\mathrm{MBC}$ rider & $114(8.6 \%)$ & $32(15.9 \%)$ & $82(7.3 \%)$ & \\
\hline Pedal cyclist & 77 (5.8\%) & $23(11.4 \%)$ & $54(4.8 \%)$ & \\
\hline Violence & $72(5.4 \%)$ & $10(5 \%)$ & $62(5.5 \%)$ & \\
\hline Pedestrian & $114(8.6 \%)$ & $8(4 \%)$ & $106(9.5 \%)$ & \\
\hline MVC passenger & $85(6.4 \%)$ & $8(4 \%)$ & $77(6.9 \%)$ & \\
\hline Industrial & $27(2 \%)$ & $8(4 \%)$ & $19(1.7 \%)$ & \\
\hline MBC passenger & $12(0.9 \%)$ & $4(2 \%)$ & $8(0.7 \%)$ & \\
\hline Penetrating or cutting injury & 43 (3.3\%) & $3(1.5 \%)$ & $40(3.6 \%)$ & \\
\hline Sport and other & $52(3.9 \%)$ & $5(2.5 \%)$ & $47(4.2 \%)$ & \\
\hline
\end{tabular}


Table 3 Depression anxiety stress levels in trauma patients at baseline, 3 months, and 6 months post injury

\begin{tabular}{|c|c|c|c|c|}
\hline Time point & Rating & Depression & Anxiety & Stress \\
\hline \multirow[t]{5}{*}{ Baseline } & Mean (SD) & $9.4(9.8)$ & $10.3(8)$ & $14.5(10.6)$ \\
\hline & Normal & $127(63.2 \%)$ & $83(41.3 \%)$ & $112(55.7 \%)$ \\
\hline & Mild- Moderate & $42(20.9 \%)$ & $73(36.3 \%)$ & $53(26.4 \%)$ \\
\hline & Severe- Extremely Severe & $32(15.9 \%)$ & $45(22.4 \%)$ & $36(17.9 \%)$ \\
\hline & Total participants with above normal rating & $36.8 \%$ & $58.7 \%$ & $44.3 \%$ \\
\hline \multirow[t]{5}{*}{3 months } & Mean (SD) & $9.3(9.6)$ & $6.4(8)$ & $12.8(10)$ \\
\hline & Normal & $73(59.8 \%)$ & $80(65.6 \%)$ & $77(63.1 \%)$ \\
\hline & Mild- Moderate & $30(24.6 \%)$ & $21(17.2 \%)$ & $29(23.8 \%)$ \\
\hline & Severe- Extremely Severe & $19(15.6 \%)$ & $21(17.2 \%)$ & $16(13.1 \%)$ \\
\hline & Total participants with above normal rating & $49(40.2 \%)$ & $42(34.4 \%)$ & $45(36.9 \%)$ \\
\hline \multirow[t]{5}{*}{6 months } & Mean (SD) & $5.9(7.7)$ & $4.2(5.1)$ & $8.9(7.9)$ \\
\hline & Normal & $83(76.1 \%)$ & $85(78 \%)$ & $84(77.1 \%)$ \\
\hline & Mild-Moderate & $21(19.3 \%)$ & $20(18.3 \%)$ & $21(19.3 \%)$ \\
\hline & Severe- Extremely Severe & $5(4.6 \%)$ & $4(3.7 \%)$ & $4(3.7 \%)$ \\
\hline & Total participants with above normal rating & $26(23.9 \%)$ & $24(22.0 \%)$ & $25(22.9 \%)$ \\
\hline
\end{tabular}

Of the participants who completed the interview 3 months post injury, 49 (40.2\%) had symptoms of depression above the normal range, $42(34.4 \%)$ had symptoms of anxiety above the normal range and 45 (36.9\%) had symptoms of stress that were above the normal range. Of these, 19 (15.6\%), reported severe to extremely severe symptoms of depression, 21 (17.2\%) in anxiety and $16(13.1 \%)$ reported severe to extremely severe symptoms of stress.

At 6 months after injury, 26 (23.9\%) of participants reported symptoms of depression that above the normal range, $24(22.0 \%)$ reported symptoms of anxiety above the normal range and 25 (23.0\%) reported symptoms of stress above the normal range. Of these participants $5(4.6 \%), 4(3.7 \%)$ and $4(3.7 \%)$ reported severe to extremely severe symptoms of depression, anxiety and stress respectively (Table 3 ).

\section{Characteristics of participants with moderate and above levels of depression, anxiety and stress}

The mean age of participants reporting moderate and above levels of depression, anxiety and stress at baseline, 3 and/or 6 months remained similar (48-50 years) with no particular age group reporting a significant increase or decrease in depression anxiety or stress scores at any one time point. Injury severity, mechanism of injury and gender also remained consistent across the time period (Table 4). Participants who had been admitted to ICU were more likely to report moderate and above level of depression, anxiety and stress at $3(\mathrm{p}=0.03)$ and 6 months $(\mathrm{p}=0.04)$ than those who were not admitted (Table 5).

\section{Predictors of high depression anxiety and stress at 6 months post injury}

Participants who had been admitted to ICU were 4 times as likely to report moderate or above level of depression, anxiety and stress in any of the 3 DASS-21 subscales at 6 months post injury when compared to those who had not been admitted (OR 4.440, CI [1.109- 17.767]). Participants who reported moderate or above levels of depression, anxiety and stress at baseline and 3 months (persistent) post injury were nearly 3 times as likely to report moderate or above levels of depression, anxiety and stress at 6 months post injury (OR 3.071, CI [1.0508.988]) when compared to patients who did not experience any elevated levels of depression, anxiety and stress at all. Participants who experienced late onset of depression, anxiety and stress (normal at baseline but moderate and above at 3 months were nearly 6 times as likely to report psychological distress at 6 months following injury when compared to those who did not experience any elevated levels of depression, anxiety and stress at all (OR 5.896, CI [1.390- 25.031]) (Table 6).

\section{Discussion}

In this study, depression, anxiety and/or stress occurred following injury in a high proportion of patients during hospitalization (58.7\%), and at $3(40.2 \%)$ and 6 months following injury (23.9\%). The severity of these symptoms ranged from mild to extremely severe.

The factor found to be primarily associated with the incidence of depression, anxiety and stress symptoms at three-month post injury in this study was an Intensive Care Unit admission. The factors associated 
Table 4 Characteristics of patients with high depression, anxiety and stress levels at baseline, 3 and 6 months

\begin{tabular}{|c|c|c|c|c|c|c|c|c|c|}
\hline \multirow[t]{2}{*}{ Characteristics } & \multirow{2}{*}{$\begin{array}{l}\text { Baseline DASS- } 21 \\
\text { Moderate and above } \\
\text { any subscale }\end{array}$} & \multirow{2}{*}{$\begin{array}{l}\text { Baseline DASS-21 } \\
\text { Normal or mild } \\
\text { any subscale }\end{array}$} & \multirow[t]{2}{*}{ Stat } & \multirow{2}{*}{$\begin{array}{l}3 \text { month DASS- } 21 \\
\text { Moderate and above } \\
\text { any subscale }\end{array}$} & \multirow{2}{*}{$\begin{array}{l}3 \text { month DASS-21 } \\
\text { Normal or mild } \\
\text { any subscale }\end{array}$} & \multirow[t]{2}{*}{ Stat } & \multirow{2}{*}{$\begin{array}{l}6 \text { month DASS- } 21 \\
\text { Moderate and above } \\
\text { any subscale }\end{array}$} & \multirow{2}{*}{$\begin{array}{l}6 \text { month DASS- } 21 \\
\text { Normal or mild } \\
\text { any subscale }\end{array}$} & \multirow[t]{2}{*}{ Stat } \\
\hline & & & & & & & & & \\
\hline No. participants & 114 & 87 & & 50 & 73 & & 28 & 81 & \\
\hline Mean age (yrs) ${ }^{\wedge}$ (SD) [Range] & $50(18)[18-89]$ & 48 (18) [17-94] & $p=0.32$ & 48 (17) [20-88] & $52(16)[21-94]$ & $p=0.20$ & 50 (17) [20-82] & 53 (16) [23-94] & $p=0.36$ \\
\hline \multicolumn{10}{|l|}{ Gender* } \\
\hline Female & $34(29.8 \%)$ & $17(19.5 \%)$ & $p=0.97$ & 15 (30\%) & $16(21.9 \%)$ & $p=0.31$ & $8(28.6 \%)$ & 19 (23.5\%) & $p=0.59$ \\
\hline Male & $80(70.2 \%)$ & $70(80.5 \%)$ & & 35 (70\%) & $57(78.1 \%)$ & & $20(71.4 \%)$ & $62(76.5 \%)$ & \\
\hline $\begin{array}{l}\text { Injury Severity Score (ISS) } \\
\text { median (IQR) }\end{array}$ & $8(4-14)$ & $9(5-14)$ & $p=0.62$ & $9(5-17)$ & $8(5-13)$ & $p=0.37$ & $9.5(4-21.5)$ & $9(5-13)$ & $p=0.55$ \\
\hline \multicolumn{10}{|l|}{ Polytrauma* } \\
\hline Yes & 77 (67.5\%) & $66(75.9 \%)$ & $p=0.20$ & 40 (80\%) & $52(71.2 \%)$ & $p=0.27$ & $16(57.1 \%)$ & 64 (79\%) & $p=0.02$ \\
\hline No & $37(32.5 \%)$ & $21(24.1 \%)$ & & $10(20 \%)$ & $21(28.8 \%)$ & & $12(42.9 \%)$ & $17(21 \%)$ & \\
\hline \multicolumn{10}{|l|}{$\begin{array}{l}\text { Intensive Care Unit (ICU) } \\
\text { admission* }\end{array}$} \\
\hline Yes & $13(11.4 \%)$ & $6(6.9 \%)$ & $p=0.28$ & $9(18 \%)$ & $4(5.5 \%)$ & $p=0.03$ & $6(21.4 \%)$ & $6(7.4 \%)$ & $p=0.04$ \\
\hline No & $101(88.6 \%)$ & $81(93.1 \%)$ & & 41 (82\%) & 69 (94.5\%) & & $22(78.6 \%)$ & 75 (92.6\%) & \\
\hline \multicolumn{10}{|l|}{ Injury mechanism* } \\
\hline Fall > 1 metre & 32 (28.1\%) & $24(27.6 \%)$ & $p=0.18$ & $14(28 \%)$ & $18(24.7 \%)$ & $p=0.08$ & $9(32.1 \%)$ & $21(25.9 \%)$ & $p=0.27$ \\
\hline MVC driver & $31(27.2 \%)$ & $13(14.9 \%)$ & & 10 (20\%) & 16 (21.9\%) & & $8(28.6 \%)$ & 16 (19.8\%) & \\
\hline MBC rider & 17 (14.9\%) & 15 (17.2\%) & & $9(18 \%)$ & $12(16.4 \%)$ & & $6(21.4 \%)$ & $14(17.3 \%)$ & \\
\hline Pedal cyclist & $8(7 \%)$ & 15 (17.2\%) & & $3(6 \%)$ & 16 (21.9\%) & & $0(0 \%)$ & 15 (18.5\%) & \\
\hline Violence & $4(3.5 \%)$ & 19 (21.8\%) & & $5(10 \%)$ & $0(0 \%)$ & & $2(7.1 \%)$ & $2(2.5 \%)$ & \\
\hline Pedestrian & $5(4.4 \%)$ & $6(6.9 \%)$ & & $3(6 \%)$ & $1(1.4 \%)$ & & $0(0 \%)$ & $3(3.7 \%)$ & \\
\hline MVC passenger & $3(2.6 \%)$ & $5(5.7 \%)$ & & $2(4 \%)$ & $1(1.4 \%)$ & & $1(3.6 \%)$ & $2(2.5 \%)$ & \\
\hline Industrial & $5(4.4 \%)$ & $3(3.4 \%)$ & & $1(2 \%)$ & $5(6.8 \%)$ & & $2(7.1 \%)$ & $3(3.7 \%)$ & \\
\hline MBC passenger & $4(3.5 \%)$ & $0(0 \%)$ & & $1(2 \%)$ & $1(1.4 \%)$ & & $0(0 \%)$ & $2(2.5 \%)$ & \\
\hline Penetrating & $2(1.8 \%)$ & $1(1.1 \%)$ & & $1(2 \%)$ & $1(1.4 \%)$ & & $0(0 \%)$ & $0(0 \%)$ & \\
\hline Other & $3(2.6 \%)$ & $2(2.3 \%)$ & & $1(2 \%)$ & $2(2.7 \%)$ & & $0(0 \%)$ & $3(3.7 \%)$ & \\
\hline
\end{tabular}

${ }^{*}$ Chi-Square test ${ }^{+}$Mann-Whitney $\mathrm{U}$ test ${ }^{\wedge} \mathrm{t}$-test. 
Table 5 Bivariate relationship between predictors and high levels of depression, anxiety and stress at $\mathbf{6}$ months post injury

\begin{tabular}{lll}
\hline Variables & Test statistics & Significance \\
\hline $\begin{array}{l}\text { High levels of depression anxiety } \\
\text { or stress }\end{array}$ & $x^{2}=9.600, d f=3$ & $p=0.022$ \\
Age & $T=0.925, d f=107$ & $p=0.357$ \\
Gender & $x^{2}=0.292, d f=1$ & $p=0.590$ \\
ISS & Mann-Whitney & $p=0.554$ \\
Polytrauma & $x^{2}=5.096, d f=1$ & $p=0.024$ \\
ICU admission & $x^{2}=4.175, d f=1$ & $p=0.041$ \\
Injury mechanism & $x^{2}=11.039, d f=9$ & $p=0.273$ \\
\hline
\end{tabular}

with depression, anxiety and stress symptoms six months post injury were again, an Intensive Care Unit admission, and secondly, the reporting of depression, anxiety and/or stress symptoms in the moderate/severe/extremely severe categories at 3 months post injury.

Although ICU admission was a predictor of persistent depression, anxiety and stress symptoms, all patients admitted to hospital following injury should be screened as the majority of participants reporting moderate and above depression, anxiety and stress symptoms were not severely injured and may not have had an ICU admission. These findings are consistent with other literature describing the mental health outcomes in both the injured [17-20] and non-injured population [18-20]. The finding that a large proportion of participants had high depression, anxiety and stress scores at 3 months suggests routine longitudinal follow-up is needed and supports findings by Richmond et al., [21] who showed that injured participants experience an increase in psychological distress at 3 months after discharge from hospital when compared to baseline findings. The finding that ISS and polytrauma is not a predictor of depression, anxiety and stress after injury is also consistent with the existing evidence [22-24].

\begin{tabular}{|c|c|c|c|}
\hline Variables in logistic regression & Odd ratios & 95\% C.I & Sig. \\
\hline Polytrauma & 0.191 & $0.065-0.562$ & 0.003 \\
\hline ICU admission & 4.440 & $1.109-17.767$ & 0.035 \\
\hline $\begin{array}{l}\text { Persistent (mod/above depression } \\
\text { anxiety or stress at baseline and } \\
3 \text { months) }\end{array}$ & 3.071 & $1.050-8.988$ & 0.041 \\
\hline $\begin{array}{l}\text { Late onset (mod/above depression } \\
\text { anxiety or stress first reported at } \\
3 \text { months) }\end{array}$ & 5.896 & $1.390-25.013$ & 0.016 \\
\hline
\end{tabular}

Model Significance: $x^{2}=19.237 .19, \mathrm{df}=4, \mathrm{p}=0.001$; Nagelkerke $\mathrm{R}^{2}=0.238$. Hosmer-Lemeshow goodness of fit statistic: $x^{2}=3.017, \mathrm{df}=4, \mathrm{p}=0.555$.
The study findings support the use of the DASS-21 in the injured population and the findings indicate that patients require mental health follow up post injury. There is a known lack of mental health follow up post discharge from hospital following injury [7]. The process for routine screening and related resource implications needs to be considered. If patients attend a trauma outpatient clinic for routine follow up they could be screened by the treating clinician or a clinic nurse in addition to their clinical follow up after injury. Or, if in hospital resources are limited, at the very least patients who have had an ICU admission should be targeted.

As a result of this study, in February 2014 the study site commenced screening patients for mental health sequelae using the DASS-21 in the trauma outpatient clinic in conjunction with their clinical follow up. A process for referral of patients reporting symptoms to clinical psychologists and/or in cases of active suicidality to the site acute mental health team was developed by the clinic trauma nurse in consultation with the site mental health team. Over ten patients requiring referral for mental health intervention have been identified through this process, which is being monitored for potential further evaluation. This does, however, exclude patients who do not return to the clinic for review who may also be at risk. To mitigate this, in all patient discharge letters, general advice about the emotional sequelae of injury is now included in conjunction with instruction to follow up with their General Practitioner or the Trauma outpatient clinic should they experience symptoms of depression, anxiety and stress post injury. The development of a standardized discharge information pack, informed by the study findings is under development, which includes information regarding symptom recognition, risk factors and resources for follow-up.

Routine in-hospital screening and follow up would promote anticipatory guidance for care and this is essential for the holistic wellbeing and health outcomes of the injured patient. The early identification of symptoms of depression, anxiety and stress post-injury would facilitate early intervention. Early intervention for mental health in general may also prevent the progression of Acute Stress Disorder symptoms to Post Traumatic Stress Disorder [25], particularly as anxiety symptoms may be correlated with the development of PTSD symptoms [26].

Future research could include the relationship between DAS and PTSD in this clinical population, the presence of co-morbid physical and mental illness and ongoing physical illness following hospital discharge. Qualitative exploration to explain the study findings would assist in understanding the role that physical and psychosocial factors relating to injury play in the development of negative emotion states, and the factors that may prevent or ameliorate these injury-related impacts. The 
significance of social support for the injured patient, for example, has been previously identified [27].

The limitations of this study included the small sample size and loss to follow up making it impossible to exclude the possibility that these participants did not have ongoing symptoms of depression, anxiety and stress. The study also attracted a small response rate. For example, there were significantly fewer patients who required an ICU admission in the study group than in the non study group, this could represent an under reporting of the magnitude of the incidence of elevated depression, anxiety and stress given that an ICU admission was a predictor of above normal levels. This group could also have been precluded from participating due to the severity of their cognitive impairment following traumatic brain injury. Further, there was no reliable recorded patient data on pre-existing mental health diagnosis, resulting in the inability to acknowledge pre-existing symptoms. Nor was the misuse of alcohol and other drugs recorded, which are known factors associated with the symptoms of depression and anxiety [28].

\section{Conclusion}

Depression, anxiety and stress symptoms occur following injury in a high proportion of patients during hospitalization, and at 3 and 6 months following injury, particularly those requiring intensive care. The DASS-21 has the ability to identify longer-term symptoms of depression, anxiety and stress in injured patients. All injured patients would benefit from routine mental health screening, particularly at 3 months following injury.

\section{Competing interests}

The authors declare that they have no competing interests.

\section{Authors' contributions}

All authors contributed to this work. KC, KF and TW designed the study. TW led the literature review into existing knowledge on the topic. Data collection and management was performed by TW. Data analysis was conducted by ML, TW and KC. The data were interpreted by TW, KC, ML, and KF. All authors contributed to the writing of the manuscript and throughout each process all authors discussed the results and implications. All authors read and approved the final manuscript.

\section{Acknowledgements}

The authors wish to acknowledge the generous support of the Australian College of Nursing Consortium Fund.

\footnotetext{
Author details

${ }^{1}$ Sydney Nursing School, University of Sydney, Camperdown 2050, NSW, Australia. ${ }^{2}$ Trauma Service, St George Hospital, Kogarah 2217, NSW, Australia. ${ }^{3}$ Faculty of Health, University of Canberra, Canberra 2617, ACT, Australia.
}

Received: 11 July 2014 Accepted: 11 March 2015

Published online: 28 March 2015

\section{References}

1. World Health Organisation. World Health Statistics 2010: World Health Organisation. Geneva: WHO; 2010.
2. Sluys K, Haggmark T, Iselius L. Outcome and quality of life 5 years after major trauma. J Trauma. 2005;59(1):223-32.

3. American Psychiatric Association. Diagnostic and Statistical Manual of Mental Disorders: 5th Edition. Washington, DC: American Psychiatric Publishing (APPI); 2013. p. 991.

4. Bryant B, Knights K. Pharmacology for Health Professionals. Third ed: Elsevier; 2011. 1062 p.

5. Zatzick DF, Russo JE, Katon W. Somatic, posttraumatic stress, and depressive symptoms among injured patients treated in trauma surgery. Psychosomatics. 2003;44(6):479-84.

6. Zatzick D, Jurkovich GJ, Rivara FP, Wang J, Fan MY, Joesch J, et al. A national US study of posttraumatic stress disorder, depression and work and functional outcomes after hospitalisation for traumatic injury. Ann Surg. 2008;248:429-237.

7. Wiseman T, Foster K, Curtis K. Mental health following traumatic physical injury: an integrative literature review. Injury. 2013;44(11):1383-90.

8. O'Donnell ML, Creamer M, Elliot P, Atkin C, Kossmann T. Determinants of quality of life and role-related disability after injury: impact of acute psychological responses. J Trauma. 2005;59(1):1328-35.

9. Salyers MP, Evans LJ, Bond GR, Meyer PS. Barriers to assessment and treatment of posttraumatic stress disorder and other trauma-related problems in people with severe mental illness: clinician perspectives. Community Ment Health J. 2004;40(1):17-31.

10. Ng F, Trauer T, Dodd S, Callaly T, Campbell S, Berk M. The validity of the 21-Item version of the depression anxiety stress scales as a routine clinical outcome measure. ACTA Neuropsychiatrica. 2007;19:304-10.

11. Lovibond SH, Lovibond PF. Manual for the Depression Anxiety Stress Scales. 2nd ed. Sydney: School of psychology, University of NSW; 1995.

12. Brown TA, Chorpita BF, Korotitsch W, Barlow DH. Psychometric properties of the depression anxiety and stress scales (DASS) in clinical samples. Behav Res Ther. 1997;35(1):79-89.

13. Mitchell M, Burns N, Dorsrtyn DS. Screening for depression and anxiety in spinal cord injury with DASS 21. Spinal Cord. 2008;46:547-51.

14. Polit DF, Beck CT. Essentials of nursing research: methods, appraisal, and utilization (6th Edition). Philadelphia: Library of Congress Cataloging-inPublication Data; 2006. 554 p.

15. Palmer CS, Franklyn M. Assessment of the effects and limitations of the 1998 to 2008 Abbreviated Injury Scale map using a large population-based dataset. Scand J Trauma Resusc Emerg Med. 2011;19(1):1-10.

16. SPSS. Statistical Program for the Social Sciences version 20. Armonk: IBM; 2012.

17. Alfred Health. Caring for the Severely Injured in Australia: . Melbourne: Inaugural Report of the Australian Trauma Registry 2010 to 2012; 2014

18. Corrigan I, Samuelson KAM, Fridlund B, Thomé B. The meaning of posttraumatic stress-reactions following critical illness or injury and intensive care treatment. Intensive and Crit Care Nurs. 2007;23(4):206-15.

19. Rattray JE, Hull AM. Emotional outcome after intensive care: Literature review. J Adv Nurs. 2008;64(1):2-13.

20. Zetterlund P, Pios K, Berghom I, Ringdal M. Memories from intensive care unit persist for several years--A longitudinal prospective multi-centre study. Intensive Crit Care Nurs. 2012;28:159-67.

21. Richmond TS, Thompson HJ, Kauder D, Robinson KM, Strumpf NE. A feasibility study of methodological issues and short-term outcomes in seriously injured older adults. Am J Crit Care. 2006;15(2):158-65.

22. Starr AJ, Smith WR, Frawley WH, Borer DS, Morgan SJ, Reinert CM, et al. Symptoms of Posttraumatic stress disorder after orthopaedic trauma. J Bone Joint Surg. 2004;86-A(6):1115-21.

23. O'Donnell ML, Creamer M, Pattison P, Atkin C. Psychiatric morbidity following injury. Am J Psychiatry. 2004;161(1):507-14.

24. Browne AL, Appleton S, Fong K, Wood F, Coll F, de Munck S, et al. A pilot randomized controlled trial of an early multidisciplinary model to prevent disability following traumatic injury. Disabil Rehabil. 2013:35(14):1149-63.

25. McKibben JB, Bresnick MG, Wiechman Askay SA, Fauerbach JA. Acute stress disorder and posttraumatic stress disorder: A prospective study of prevalence, course, and predictors in a sample with major burn injuries. J Burn Care Res. 2008;29(1):22-35.

26. Quale AJ, Schanke A, Froslie KF, Roise O. Severity of injury does not have any impact on Post traumatic stress symptoms in severely injured patients. Injury. 2009;40:498-505. 
27. Sleney J, Christie N, Earthy S, Lyons RA, Kendrick D, Towner E. Improving recovery - Learning from patients' experiences after injury: A qualitative study. Injury. 2012;45:312-9.

28. Grant BF, Stinson FS, Dawson DA, Chou P, Dufour MC, Compton W, et al. Prevalence and co-occurrence of substance use disorders and independent mood and anxiety disorders: Results from the national epidemiologic survey on alcohol and related conditions. Arch Gen Psychiatry. 2004;61(8):807-16.

Submit your next manuscript to BioMed Central and take full advantage of:

- Convenient online submission

- Thorough peer review

- No space constraints or color figure charges

- Immediate publication on acceptance

- Inclusion in PubMed, CAS, Scopus and Google Scholar

- Research which is freely available for redistribution 